\title{
The damage mechanism of water tower in Shaanxi Provence during Wenchuan Earthquake
}

\author{
Chunfeng Li1, , Xuyang Luo ${ }^{2}$, Rui Duan ${ }^{1, \mathrm{~b}}$, Youliang Shu ${ }^{1, \mathrm{c}}$, Wangqiang Dai ${ }^{1, \mathrm{~d}}$, Chung Liu ${ }^{1, \mathrm{e}}$, Qingmin Yan ${ }^{1, \mathrm{f}}$, Tianshe \\ She ${ }^{1, g}$, Xinghai Shi ${ }^{1, h}$ \\ ${ }^{1}$ Earthquake Administration of Shaanxi Province, 710086 Xi'an, China \\ ${ }^{2}$ Earthquake Administration of Baoji City, 721004 Baoji, China
}

\begin{abstract}
Through the collection, collation and analysis of the data about damage of Water tower in Shaanxi Provence during 12 May 2008 Wenchuan Earthquake, the mechanism of long-period damage of the water tower is given. The analysis shows that, in Hanzhong basin, Ankang basin, and Weihe basin, serious damage should be caused by the long-period effect of basin of large earthquake in the far field. That magnitude of Wenchuan Earthquake is high, three basins are at the direction where the Wenchuan Earthquake wave propagated, and the epicentre is from 400 to $600 \mathrm{~km}$ determines that the Wenchuan earthquake has the condition producing long-period effect in the three basins. In addition, the basins have very thick deposits, as well as possible basin edge effect may enhance long period damage. The damage of long-period of water tower results from the resonance between water tower and long-period ground motion.
\end{abstract}

\section{Introduction}

Ms 8.0 Wenchuan, earthquake occurred in 12 May 2008, in Sichuan Province, China. In 10 cities (including 92 counties, and 9357 administrative villages.) away from hundreds of miles, in Shaanxi province, there were different degrees of earthquake disaster. In basin regions where Hanzhong, Ankang, Baoji, Xi'an, and Xianyang are located, there were serious earthquake disasters in far field with large magnitude earthquake. Serious damage never had occurred in so far distance in the world before. Among all the damages, the damage of water tower is more prominent. In previous study (Men et al, 2008; Wang, 2009; Xue, 2009,Wang, 2011; Wang, 2008; Chen, 2010; Shu, 2008; Ma, 2010; Xu,2010), damage of Wenchuan Earthquake to tower is seldom analysed, and seismic damage mechanism is described rarely. This paper aims to analyse the type, distribution, intensity and other factors of damage of water tower, to reveal the mechanism of the seismic damage of water tower of Wenchuan Earthquake in Shaanxi province.

\section{Damage of water tower}

During Wenchuan Earthquake in 2008, in 400-800km away from the epicentre (Fig.1) outside of Shaanxi Province, serious disaster occurred, causing serious casualties of property and personnel. Especially in the basin area where Hanzhong, Ankang, Baoji, Xi'an, and Xianyang are located (Table 1, Table 2, Table 3, and Fig. 1 ), the damage is relatively serious.

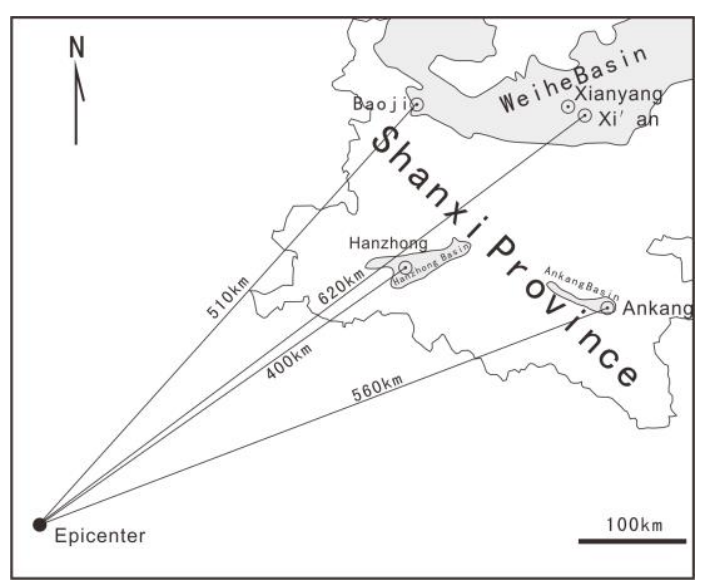

Figure 1. Epicentre of Wenchuan Earthquake and distribution of the basins in Shaanxi Province.

Table 1. Part of statistics results of damage of water tower in Xi'an.

\begin{tabular}{|c|c|}
\hline Lianhu District & 1 \\
\hline Yanta District & 2 \\
\hline Changan Ditrict & 4 \\
\hline $\mathrm{Hu}$ County & 27 \\
\hline Zhouzhi County & 26 \\
\hline
\end{tabular}


Table 2. Part of statistics results of damage of water tower in

\begin{tabular}{|c|c|}
\hline \multicolumn{2}{|c|}{ Xianyang. } \\
\hline Bin County & 14 \\
\hline Yongshou County & 11 \\
\hline Xunyi County & 10 \\
\hline
\end{tabular}

Table 3. Part of statistics results of damage of water tower in Baoji.

\begin{tabular}{|c|c|}
\hline Jintai District & 8 \\
\hline Yongshou County & 6 \\
\hline Xunyi County & 8 \\
\hline Chenchang District & 9 \\
\hline Fengxiang County & 11 \\
\hline
\end{tabular}
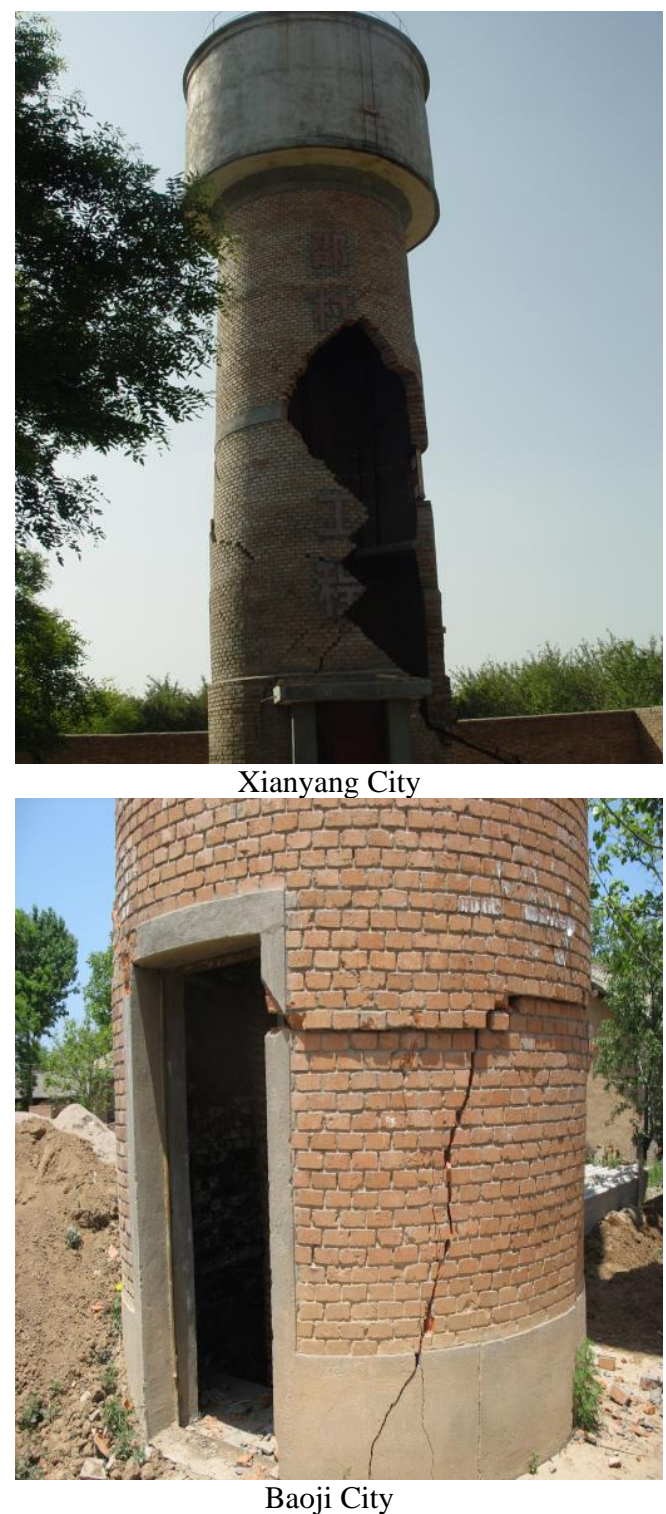

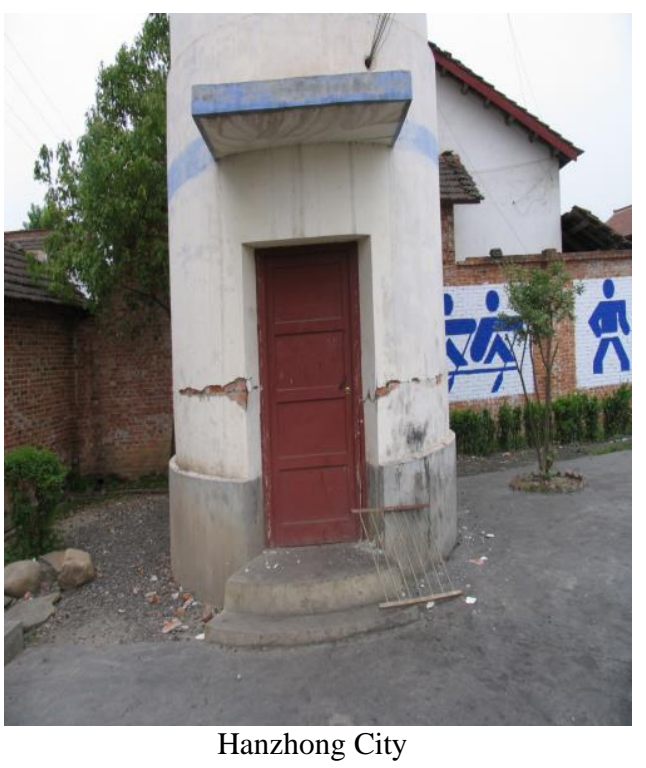

Figure 2. Damage of water tower in Shaanxi Province.

\section{Analysis of damage of water tower}

\subsection{Dynamic characteristics of water tower}

The water tower is a special structure with the sloshing characteristics. In the long-period ground motion effect, the water in the water tower can swing. Because of the sloshing of the water in water tower, natural period of water tower can increase, turning into long period structure, vulnerable to the impact of long-period ground motion.

\subsection{Long period effect of large earthquakes in the far field}

According to Zhang (2008), seismic source energy release time reached 90 seconds. There is never so long time before. In the far field, ground motion duration will increase, making the long period structure damage easily. It can be seen in Fig. 3 that according to the Wenchuan surface rupture trace, during Wenchuan earthquake, seismogenic structure mainly spread from the epicenter to the northeast. And the Hanzhoung basin, Ankang basin, Baoji basin and Weihe basin (Fig. 1) are at direction of the rupture propagation. This situation makes the study area more vulnerable to seismic wave radiation, especially when the seismic waves from the edge of oblique incident basin, edge effects of basin can occur, thereby increasing the damage resulting from long-period ground motion. As can be seen from Fig.1, the epicentral distance of the three basins is larger. Epicentral distance shows that relative to Weihe Basin where Xi'an and Xianyang are located, Wenchuan earthquake is distant and great earthquake, easily to produce low frequency long-period ground motion and increase long-period damage. 


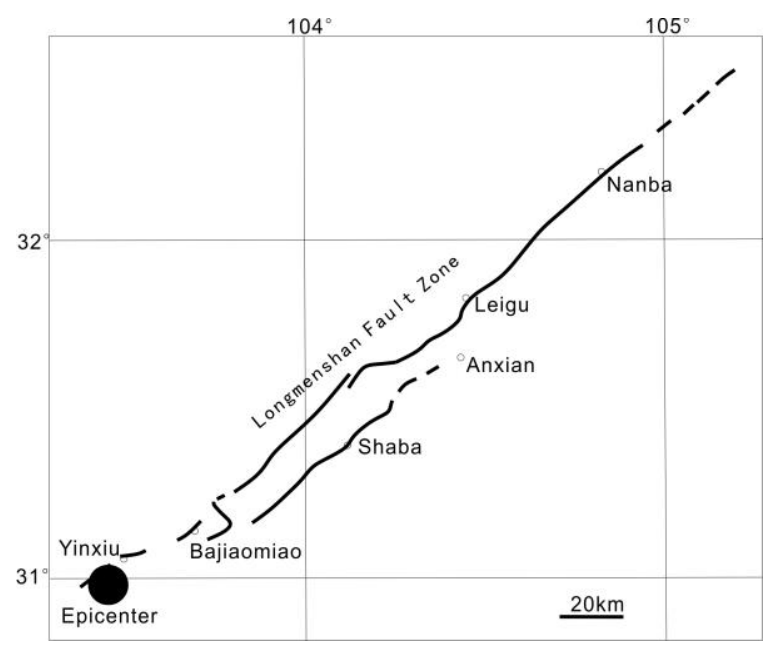

Figure 3. Surface rupture of Wenchuan.

\section{Conclusion}

The analysis shows that, in Hanzhoung basin, Ankang basin, and Weihe basin, serious damage should be caused by the long-period effect of basin of large earthquake in the far field. Magnitude of Wenchuan Earthquake is high, three basins are at the direction where the Wenchuan Earthquake wave propagated, and the epicentre is from 400 to $600 \mathrm{~km}$. This determines that the Wenchuan Earthquake has the condition producing long-period effect in the three basins. In addition, basin has very thick deposits, as well as possible basin edge effect may enhance long-period damage. The damage of long-period of water tower results from the resonance between water tower and long-period ground motion. Because of the rich long-period ground motions, and long natural period of water tower, the resonance is easy to occur. In addition, the ground motion from large earthquake in far field has long duration which can provide sufficient time for the resonance, resulting in low cycle fatigue easily, and increasing damage. The long duration of ground motion can be obviously seen in figures 4. Although the peak acceleration is only $52.7 \mathrm{~cm} / \mathrm{s}^{2}$, the duration is more than $400 \mathrm{~s}$, which can provide sufficient time for the resonance, causing long period damage. Similar phenomena appear in figures 5, 6 and 7.

Unfortunately, there are no seismological stations in the Hanzhoung basin and Ankang basin.

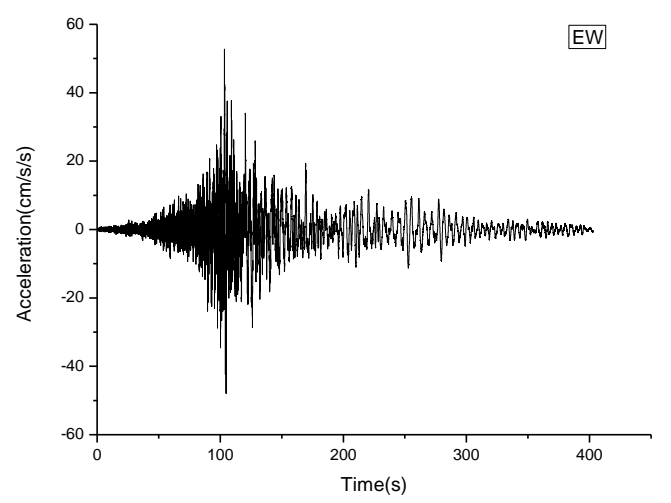

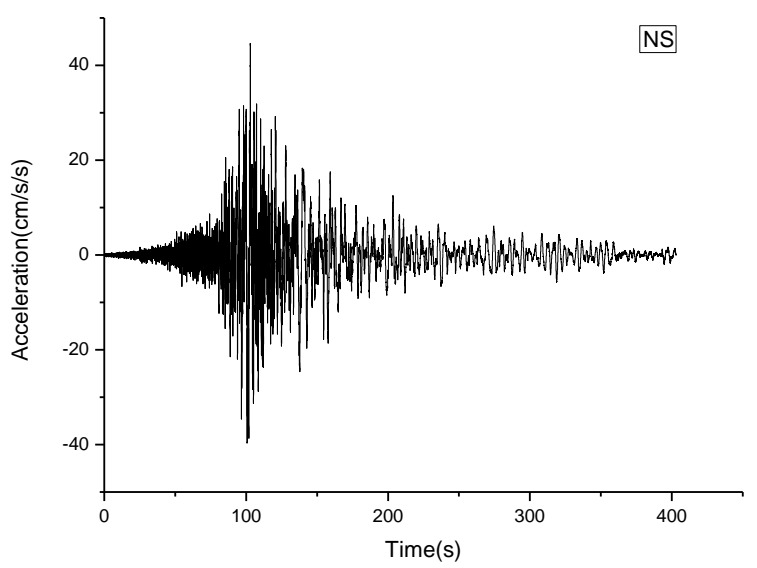

Figure 4. Records of strong ground motion of Wenchan Earthquake in Xi'an station.
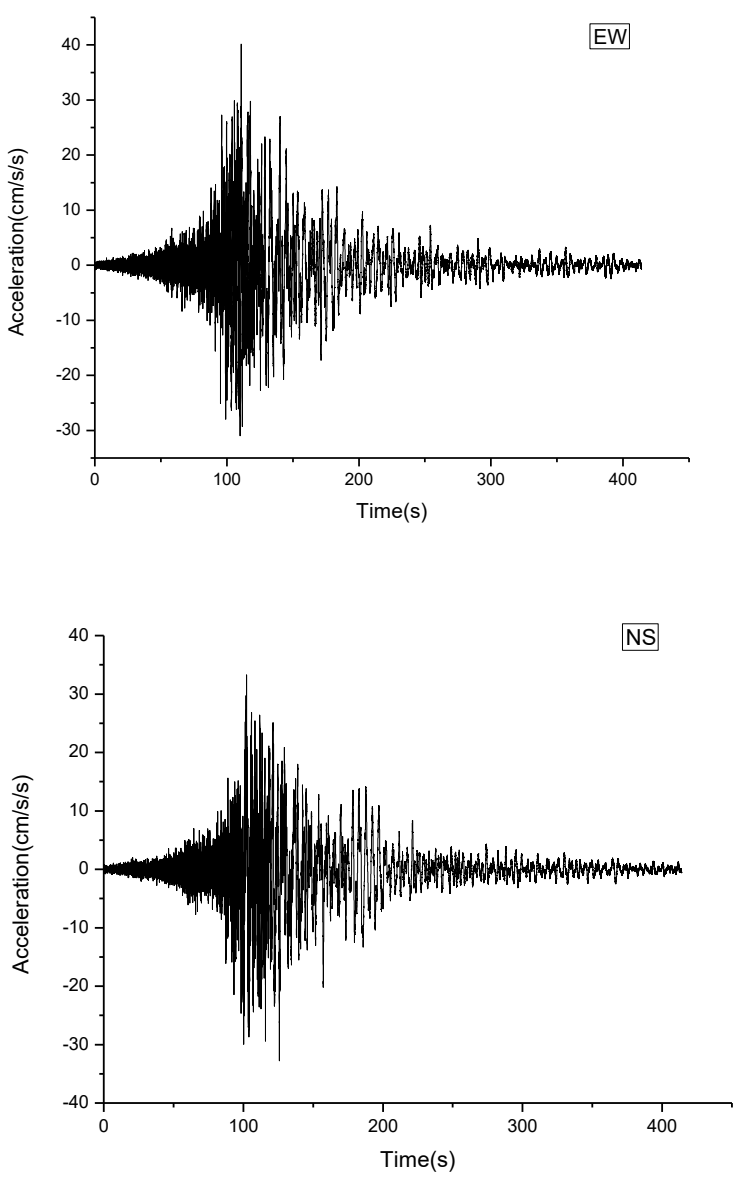

Figure 5. Records of strong ground motion of Wenchan Earthquake in Xianyang station. 

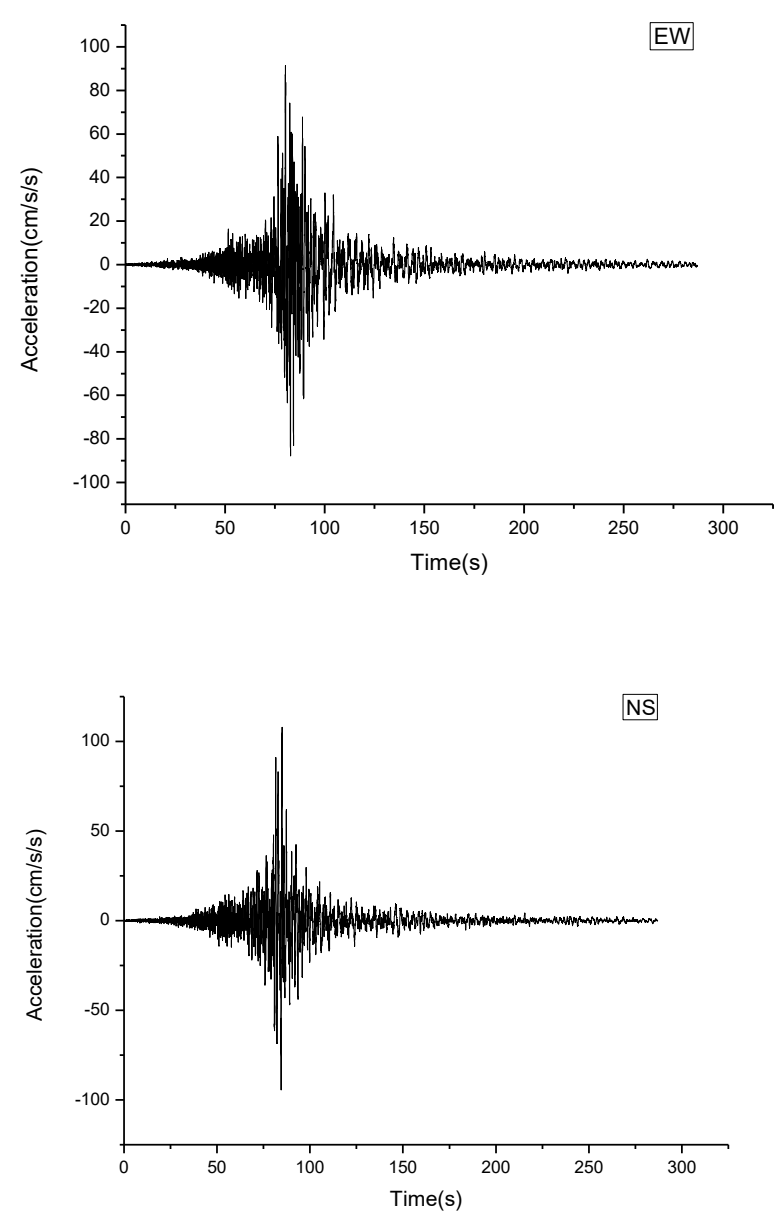

Figure 6. Records of strong ground motion of Wenchan Earthquake in Chenchang station in Baoji.

\section{Acknowledgements}

The Project Supported by Natural Science Basic Research Plan in Shaanxi Province of China(Program No. 2013JM5014), Science for Earthquake Resilience (XH12045), and Seismic Microzonation of Ankang City (SCZC2012-TP-905/1, B).

\section{References}

1. P. Chen, Water Resources and Architectural Engineering 8, 2 (2010)

2. J. Y. Ma, China science and technology 4, 345 (2010)

3. J. J. Ma, Xi'an University of Architecture \& Technology(Natural Science Edition) 40, 648 (2008)

4. Y. L. Ma, Catastrophology 23, 125 (2008)

5. H. Y. Wang, Geophysics 54, 137 (2011)

6. K. L. Wang, Xi'an University of Architecture \& Technology (Natural Science Edition) 40, 637 (2008)

7. Y. X, Shaanxi building 8, 186 (2009)

8. Y. Xue, Technology for Earthquake Disaster Prevention 4, 363 (2009)
9. Y. Zhang, Science China Earth Sciences 38, 1186 (2008)

10. L. J. Xu, ACT A SEISMOLOGICA SINICA 32, $175(2010)$ 